\title{
Obstrução nasolacrimal em criança: Ascaris lumbricoi- des como uma causa incomum
}

\author{
Nasolacrimal obstruction in a child: Ascaris lumbricoides as an unusual cause
}

Ernesto Helder Palma Araújo

Sérgio Schneider Guimarães
Este trabalho foi realizado no Centro Oftalmológico de Minas Gerais.

Um dos revisores deste artigo foi o Dr. Aristides de Atayde Neto.

Endereço para correspondência: Dr. Ernesto Helder Palma Araújo - R. Zoroastro Passos, 170/ 201 - Centro - Sete Lagoas (MG) CEP 3570-0017. Tel: (0XX31) 771- 0777

\begin{tabular}{|c|}
\hline RESUMO \\
\hline Este artigo descreve um caso incomum de obstrução de vias \\
lacrimais por Ascaris lumbricoides em uma criança de 1 ano de idade \\
e faz um breve relato de outros casos semelhantes na literatura, \\
enfatizando a necessidade de se pensar em helmintíase como provável \\
causa de obstrução lacrimal em crianças desnutridas que moram em \\
áreas de alta prevalência de parasitose intestinal.
\end{tabular}

Palavras-chave: Obstrução lacrimal; Ascaris; Epífora.

\section{INTRODUÇÃ̃O}

As etiologias do sistema de drenagem lacrimal estão ricamente descritas e pesquisadas na literatura médica, com uma gama de fatores que acometem o indivíduo segundo sua idade, presença de patologias sistêmicas, exposição a trauma facial, malformações congênitas ${ }^{1}$, iatrogenia como a migração de plugs de silicone após oclusão de ponto lacrimal para tratamento de olho seco ${ }^{2}$, presença de neoplasias envolvendo as vias lacrimais, entre outros fatores.

Nosso objetivo é descrever um caso incomum de obstrução nasolacrimal em uma criança de 1 ano de idade devido à parasitose intestinal por Ascaris lumbricoides.

\section{RELATO DE UM CASO}

Paciente de 1 ano de idade, leucoderma, residente em área rural de Sete Lagoas (MG), vítima de desnutrição acentuada apresentou episódio súbito de vômitos aquosos, com grande quantidade de vermes adultos de $A$. lumbricoides no conteúdo do vômito. Não houve relato de eliminação nasal do verme durante os episódios de vômito. Foi atendida em clínica pediátrica da EMPREMED em Sete Lagoas (MG) e liberada para tratamento domiciliar e acompanhamento ambulatorial. Posteriormente foi levada por sua mãe para consultório oftalmológico no Centro Oftalmológico de Minas Gerais em Belo Horizonte devido a epífora intensa no OD.

Ao exame oftalmológico apresentava hiperemia conjuntival universal no OD e excesso de secreção purulenta e viscosa no local com a parte anterior de um verme se exteriorizando pelo ponto lacrimal inferior direito (figuras 1 e 2).

Realizado breve sedação anestésica na criança e o verme foi retirado do canalículo lacrimal inferior por simples tração pausada, para evitar a ruptura do verme no interior do canal lacrimal do paciente. Rinoscopia 


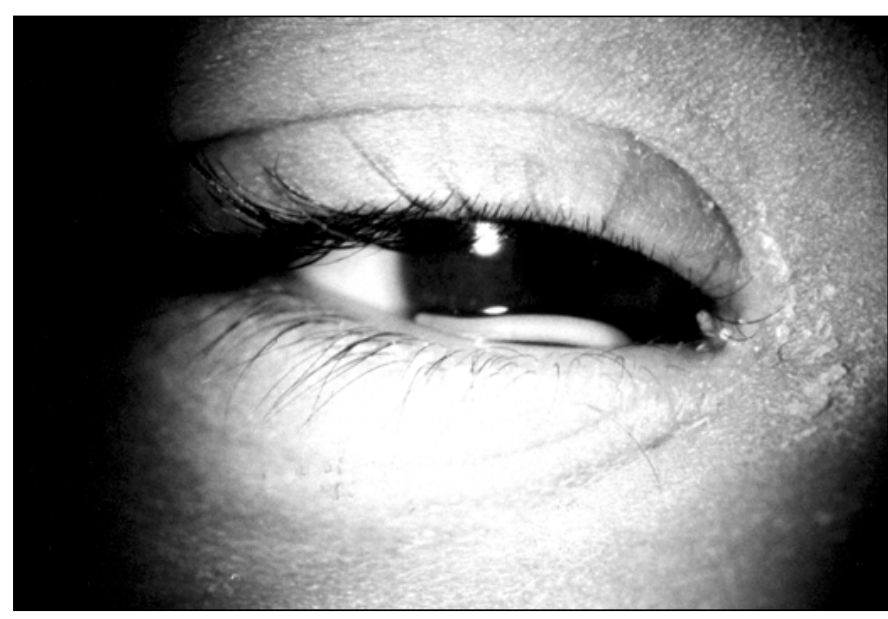

Fig. 1 - Obstrução nasolacrimal pelo Ascaris lumbricoides.

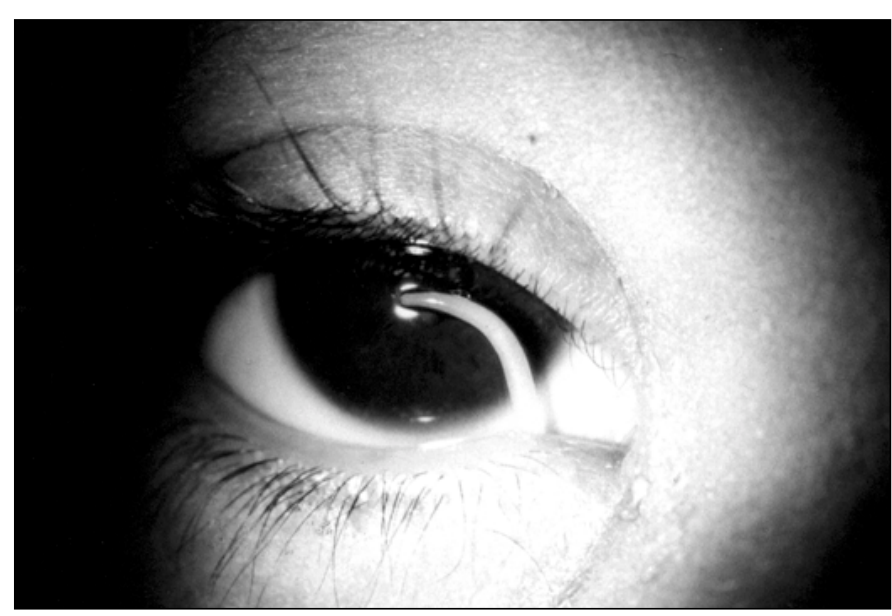

Fig. 2 - Exteriorização do helmito pelo ponto lacrimal inferior direito.

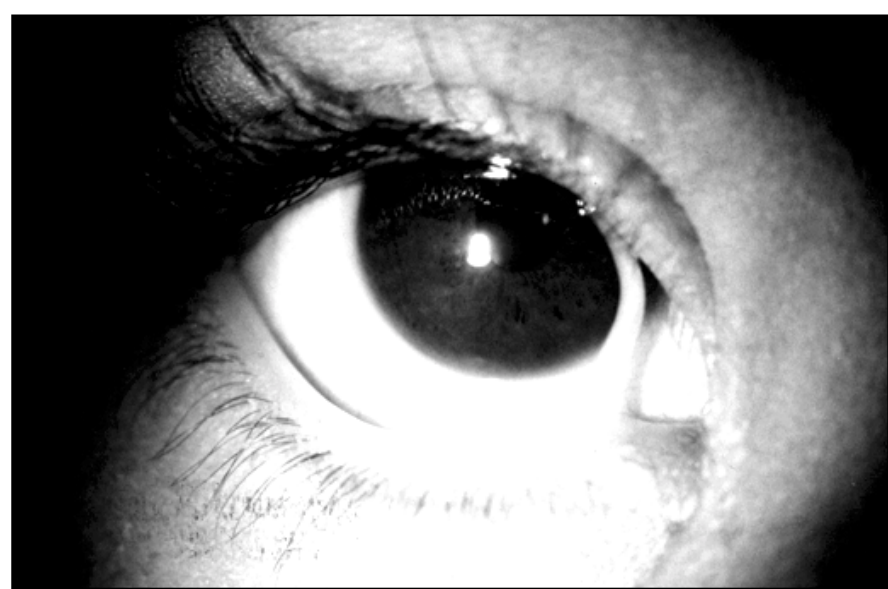

Fig. 3 - Exteriorização do helmito pelo ponto lacrimal inferior direito.

anterior foi realizada previamente, não se identificando o verme na cavidade nasal.

Após a retirada do verme, as vias lacrimais foram copiosa-

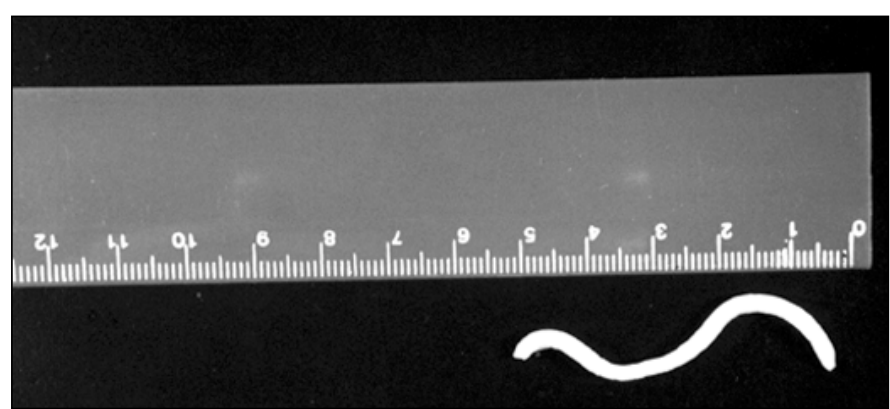

Fig. 4 - Aspecto do Ascaris lumbricoides após a retirada.

mente irrigadas com solução salina $0,9 \%$ em associação com gentamicina (solução injetável - 40mg), o que se mostrou pérveo ao fluxo da solução irrigadora.

$\mathrm{O}$ verme analisado laboratorialmente foi identificado como a fêmea do Ascaris lumbricoides (figura 3).

Feito acompanhamento oftalmológico ambulatorial do caso em questão com o uso de antibiótico tópico (gentamicina), com melhora total da hiperemia conjuntival, da epífora, e desaparecimento da secreção purulenta.

Julgamos não ser necessária a realização de nenhum método de investigação radiocontrastada posteriormente devido à total melhora do quadro.

\section{DISCUSSÃO}

O Ascaris lumbricoides Lineu (1758) é encontrado em quase todos os países do globo. É conhecido popularmente por lombriga e causa a doença conhecida como ascaridíase. Essa doença tem ampla distribuição mundial com mais de 1,4 bilhões de pessoas infectadas em todo o mundo. A maioria das infecções ocorrem em países ditos "em desenvolvimento" da Ásia, África e América Latina. De 4 milhões de pessoas infectadas nos Estados Unidos da América, uma grande porcentagem são de imigrantes de países em desenvolvimento ${ }^{3}$.

O macho do $A$. lumbricoides mede cerca de $20-30 \mathrm{~cm}$ de comprimento e extremidade posterior fortemente encurvada para a face ventral. A fêmea por sua vez mede cerca de 30-40 $\mathrm{cm}$, é mais grossa que o macho e apresenta extremidade posterior retilínea. Ambos apresentam cor leitosa, brancomarfim ou rósea.

O habitat natural desse helminto é o intestino delgado do homem, principalmente o jejuno e íleo.

A transmissão se faz através da ingestão de ovos infectantes junto com alimentos contaminados ou mesmo material subungueal ${ }^{4}$.

Quando ingeridos pelo hospedeiro os ovos infectantes vão sofrer eclosão no intestino delgado, liberando larvas que atravessam a parede intestinal, alcançam a veia cava inferior e migram para os alvéolos pulmonares. Posteriormente sobem pela árvore brônquica e traquéia, chegam até a faringe e podem ser expelidas pela expectoração ou serem deglutidas, 
sendo novamente encontradas em estágio de adulto-jovem no intestino delgado onde iniciarão a postura de novos ovos.

As larvas em infecções pequenas geralmente não causam nenhuma alteração. Em infecções maciças podem causar lesões hepáticas e pulmonares (sínd. de Loeffler). Os vermes adultos, dependendo da carga parasitária, podem causar graves alterações como a subnutrição (ação expoliadora), e obstrução intestinal.

O diagnóstico é clínico e laboratorial (pesquisa de ovos nas fezes), e o tratamento de escolha é o levamisole (85\% de eficácia). Drogas alternativas são o mebendazol, piperazina e albendazol ${ }^{5}$.

Assunto controverso é o fato de que alguns autores preferem somente tratar esta helmintíase em pacientes que estão fora da área endêmica, alegando a alta taxa de reinfestação do hospedeiro em áreas de alta prevalência da doença. Sabe-se que a longa coexistência entre o homem e o parasita intestinal tende ao equilíbrio. Somente há quebra desse equilíbrio quando ocorre aumento da virulência do parasita e/ou diminuição da resistência do hospedeiro. Outros autores já indicam o uso sistemático de anti-helmínticos em programas de saúde pública devido à grande competição nutricional entre parasita e hospedeiro. Aspecto importante é a profilaxia da doença e combate à miséria.

Chama-se “Ascaris errático” ao verme que se localiza em habitat anormal, como no apêndice cecal (causa apendicite aguda), canal colédoco (sintomas hepatobiliares), canal de Wirsung (pancreatite aguda), boca e narinas, trompa de Eustáquio (otite média) ${ }^{6,7}$, intra-hepático (abcesso hepático) ${ }^{8}$, rim e uretra (pielonefrite e hidronefrose) ${ }^{9}$, e cérebro (abcesso cerebral) ${ }^{10}$.

No caso descrito, a presença ectópica do Ascaris foi no ducto nasolacrimal, saco lacrimal e ducto lacrimal inferior do OD da criança. Caso semelhante foi relatado por Kanapumbi e Lubeji ${ }^{11}$ no Zaire em 1996 em uma criança de 9 meses de idade acometida por uma obstrução do canal lacrimal pelo helminto, mas diferentemente do nosso caso, por um macho adulto de $A$. lumbricoides. Ittyerah TP et al ${ }^{12}$, e Roche PJ ${ }^{13}$ também relataram a presença do helminto nas vias lacrimais. Em nosso meio Cunha MC et al ${ }^{14}$ reportou de forma brilhante uma obstrução do ducto nasolacrimal em uma criança brasileira de 4 anos de idade por um adulto jovem de $A$. lumbricoides que envolvia tanto os canalículos lacrimais superior e inferior quanto os pontos lacrimais superior e inferior.

Já que a ascaridíase é uma doença de ampla distribuição em países subdesenvolvidos e já que as crianças nesses países constituem o grupo predominantemente acometido pela doença, é necessário que se passe a pensar na possibilidade do helminto intestinal como provável vetor de patógenos bacterianos ou mesmo causando obstrução direta das vias lacrimais em uma criança desnutrida, com exame parasitológico de fezes positivo para o Ascaris, que resida em regiões de alta prevalência da doença, mesmo que o parasita não se exteriorize pelo ponto lacrimal.

\section{SUMMARY}

This article describes an unusual case of an obstruction of the tear ducts caused by Ascaris lumbricoides in an oneyear-old child, and presents a brief report of some other cases in the medical literature, emphasizing the necessity of considering helminths as a cause of this obstruction in malnourished children who live in areas with a high prevalence of intestinal parasistes.

Keywords: Lacrimal obstruction; Ascaris; Epiphora.

\section{REFERÊNCIAS BIBLIOGRÁFICAS}

1. Cunha RP, Moreira JB. Ocular findings in Down's syndrome. Am J Ophthalmol 1996;122;2,236-44.

2. Rumelt S, Remulta H, Rubin PA. Silicone punctal plug migration resulting in dacryocystitis and canaliculitis. Cornea 1997;16:3,377-9.

3. Khroo MS. Ascariasis. Gastroenterol Clin North Am 1996;25:3,553-77.

4. Neves, Davi Pereira. Ascaris lumbricoides. In Parasitologia Humana Neves, DP. Cap. 26 - $6^{\circ}$ edição - Atheneu - Rio de Janeiro, 1986.

5. Motta JAC et al. Doenças Infecciosas da Infância e Adolescência. Cap. 89-2 edição - MEDSI - VOL II - 2000.

6. Pedro RJ et al. Parasitose intestinal. In Doenças Transmissíveis. Amato Neto V, Baldy JLS. Cap 57 - ed. Sarvier. São Paulo, Brasil, $3^{\circ}$ edição, 1991.

7. Berkowitz FE, et al. Ascaris in middle ear. S Afr Med J 1980 18;58(16):630.

8. Parodi-Hueck LE, et al. Ascaris hepatic abscess in children J Pediatr Surg 1972;7(1):69.

9. Taylor KL. Ascaris of the kidney. Ped Pathol Lab Med 1995;15:4,609-15.

10. Stephen B. Tatter, Jonathan W. Hopkins. Cerebral Manifestations of Ascaris lumbricoides. Nov 1997.

11. Kanapumbi N, Lubeji K. An ascaris in the lacrimal duct. Apropos of a case in Zaire. Sante 1996;6(4):258-9.

12. Ittyerah TP, et al. Round worm (Ascaris lumbricoides) in the lacrimal passage. Indian J Ophthalmol 1978;25(4):46.

13. Roche PJ. Ascaris in the lacrimal duct. Trans R Soc Trop Med Hyg 1971; 65(4):540.

14. Cunha MC, et al. Obstruction of the nasolacrimal duct by Ascaris lumbricoides. Ophthal Plast Reconstr Surg 1989;5(2):141-3. 